\title{
Informality and Formality in Medium-sized Companies: Contestation and Synchronization
}

\author{
Susan Marlow, ${ }^{1}$ Scott Taylor ${ }^{2}$ and Amanda Thompson ${ }^{1}$ \\ ${ }^{1}$ Department of Human Resource Management, De Montfort University, The Gateway, Leicester LE1 9BH, \\ UK, and ${ }^{2}$ Centre for Leadership Studies, University of Exeter, Exeter EX4 4ST, UK \\ Corresponding author email: smhum@dmu.ac.uk
}

\begin{abstract}
Accounts of managerial practice in small and medium-sized firms frequently draw upon notions of formality and informality. In this paper, we explore the relationship between these concepts through an analysis of managerial approaches to employment relations practice in six growing, medium-sized organizations. Drawing on recent conceptual work on informality and formality, we argue that the use of the terms in previous analyses tends to neglect the co-dependency of both the concepts and managerial approaches to the employment relationship. We present an alternative conceptualization of formalization and informalization processes that emphasizes synchronization through interactional practices. Through this analysis, we suggest that debate in this area can be reframed through thinking of informality and formality as a dualism rather than a dichotomy, and challenge the notion that small firms must, should or inevitably do move from informality to formality. From this, we construct an inclusive model of formality and informality that better reflects practice and enables further analytical development.
\end{abstract}

\section{Introduction}

The employment relationship in small and medium-sized firms has become a significant empirical location for management researchers Q1 (e.g. Gilman et al., 2002; Marlow, Patton and Ram, 2005; Moule, 1998; Ram, 1994; Ram and Edwards, 2003; Ram et al., 2001; Wilkinson, 1999). It is said to represent 'a key exemplar of analytical advance [where] research has made empirical and analytical progress' (Ram and Edwards, 2003, p. 719). Empirical evidence suggests a notable tendency to informality in managerial action, perhaps as a result of spatial

We are grateful to De Montfort University for funding this research, and to Peter Clark (Queen Mary University of London) for listening to us talk through an early data analysis and guiding us towards a more meaningful analytical framing. and social proximity of owners, managers and labour and blurred power relations (Edwards, 2003; Marlow, 2005). Small firm owners are said to have a preference for personal supervision of employees, enabling close performance monitoring but also strengthening social ties (Mazzarol, 2003). Axiomatically, a reluctance to delegate authority to specialists leads to an absence of professionally informed or managed human resources (HR) policy and practice (Cully et al., 1999; Forth, Bewley and Bryson, 2006; Mazzarol, 2003). The interaction of a personal presence and an absence of professionalized practice therefore facilitates an informally negotiated employment relationship embedded in a range of economic, political and social networks (Edwards and Ram, 2006). Hence we find that researchers have been successful in generating an analytical framework which establishes the logic for informal labour management. However, relatively little attention

C) 2009 British Academy of Management. Published by Blackwell Publishing Ltd, 9600 Garsington Road, Oxford OX4 2DQ, UK and 350 Main Street, Malden, MA, 02148, USA.

\begin{tabular}{|c|c|c|c|c|c|}
\hline & $\mathrm{B} J \mathrm{O} \mathbf{M}$ & 635 & Dispatch: 4.3 .09 & Journal: BJOM & CE: Blackwell \\
\hline & Journal Name & Manuscript No. & Author Received: & No. of pages: 13 & PE: Bindu/Gk \\
\hline
\end{tabular}


has been afforded to the manner in which the employment relationship is reordered and renegotiated as small firms grow and increasing organizational complexity encourages the adoption of greater formality.

We take this neglected area as our focus. We analyse the manner in which the employment relationship is renegotiated across the informality-formality span (Misztal, 2000) and becomes more evident during firm growth. Our analysis has two main strands. First, we seek to contextualize and position the 'formal-informal' debate within an analytical approach that reframes the relationship between formality and informality. Specifically, we consider the tensions and contradictions which arise during growth and how they are managed by the actors involved. Second, through analysis of fine grained qualitative data, the uncertain and uneven processes managers adopt when seeking to formalize the employment relationship are examined from the perspectives of employers, managers and employees. In part, we contribute to the understanding of the employment relationship in small and medium-sized firms, an area that is 'quiet on the specific people management skills that are needed by growing small businesses, or on the transition from owner manager to more professional people management systems and skills' (Phelps, Adams and Bessant, 2007, p. 9). In addition, however, we seek to generate debate on notions of formality and informality which inform the analysis of managerial actions in such firms.

\section{Negotiating informality and formality in growing organizations}

It is an article of faith that small firms are generally managed on a more informal basis than larger organizations (Barrett and Sexton, 2006; Gilman et al., 2003; Marlow, Patton and Ram, 2005; Ram, 1994). Within small firms, informality is more likely to be the managerial norm because the organization is usually overseen by the owner or one general manager, often working without formal professional understanding and few formalized systems (Harney and Dundon, 2006; Wilkinson, 1999). In place of formality, idiosyncrasy and prerogative dominate, challenging adherence to normative prescription and policy. In essence, contractually specified models or models of best practice are not followed; informal managerial practices dominate. Marchington, Carrol and Boxall (2003), however, suggest that informality should not be dismissed as ineffective in that it can be an appropriate response to organizational context. Others argue that social and spatial proximity can be drawn upon to engender employee commitment, enable swift decision making, facilitate mutual problem solving and so add to competitive advantage (Barrett and Sexton, 2006; Sen-Gupta, 2007).

Smaller firms are also more vulnerable to market pressures and, as such, their autonomy to manage labour is more likely to be shaped by external influences (Harney and Dundon, 2006). Rainnie (1989) argued that labour management in small firms is largely determined by the market, as managers are constrained by the competitive environment in which they are marginal price takers. This notion of market determinism has been repeatedly challenged (Edwards and Ram, 2006; Moule, 1998; Ram, 1994; Ram and Edwards, 2003; Ram et al., 2001) by findings and analysis that suggest there is an uncertain interaction between market forces and the internal social relations of production leading to a more negotiated employment relationship. Gilman et al. (2002, p. 54) summarize this succinctly: "the whip of the market is likely to be mediated by employee skill, scarcity value and the extent to which there are fraternal or familial relationships within a firm'.

As firms grow and become more organizationally complex, formality emerges as terms and conditions of employment are inscribed within written policies and articulated through a more professionalized form of management. In such contexts, as Marlow (2002, p. 4) notes, 'both labour and management have recourse to a set of rules, should they feel it appropriate to use them'. Care must be taken, however, not to construct a simplistic dichotomy between informality/formality and small/large firms respectively (Marlow, Patton and Ram, 2005). As Ram et al. (2001, p. 846) argue, informality and formality are dynamic constructs which coexist in differentiated forms in time and space such that 'informality in small firms is a matter of degree and not kind'. The distinction with larger, more formalized organizations lies in the manner in which formal policy and procedure surrounds 
and orders the employment relationship. Dating back at least to the Hawthorne studies (Roethlisberger and Dickson, 1939), we know that employment relations in the largest organizations operate through both formalized policies and informal interactions or negotiation (Brown, 1973; Edwards, 1986; Friedman, 1977). Managers must navigate a path between rationality and intuition, formality and informality, professional norms and personal preference or idiosyncrasy. The toleration of informality and custom and practice that persists in the context of a contested labour process (Burawoy, 1979) contributes to the structured antagonism that shapes the employment relationship.

Ultimately, managing the tension between control and consent requires some recognition that 'settling issues through unwritten understandings plays a particularly large part in the way in which the rules of employment are generated and sustained' (Edwards, 2003, p. 14). However, 'informality in large firms, although an enduring feature of the employment relationship, is a more subversive activity ... it is only ever discretionary' (Marlow, Patton and Ram, 2005, p. 7). In smaller firms the absence of professionalized knowledge or practice and the context of social and spatial proximity create a fertile environment for the persistence and dominance of informal employment relations; this makes the task of understanding the formality-informality tension more significant.

The introduction of formality challenges prevailing norms and relationships causing disruption and uncertainty; it is this process and related tensions which are of interest here. As Ram et al. (2001, p. 846) argue, very limited attention has been afforded to how informality changes over time, as 'the tendency has been to treat it as an essentially unchanging way of oiling the wheels, but we also need to consider in what direction the wheels are heading'. Phelps, Adams and Bessant (2007) also conclude that the process of formalization has an uncertain trajectory which includes periods of stasis, expansion and contraction. An ad hoc informal managerial approach is unlikely to have the scope to satisfactorily address increasingly complex problems; therefore, 'pressures for formalization occur when existing approaches lead to errors or lack the capacity to meet new demands' (Phelps, Adams and Bessant, 2007, p.10).
All of this suggests that degrees of informality and formality coexist within all organizations, and that analysis should be oriented towards understanding this interplay. However, while accounts of informal managerial actions are plentiful, as are prescriptions of how to manage formally, conceptual development in this area is largely absent. Many analyses lack definitions of any kind relating to formality or informality; at best, 'commonsense' renditions dominate or there is an assumption that 'formal' equates to rule based and 'informal' to social negotiation. This paper explores the interaction of formality and informality in a more nuanced manner, and so contributes to conceptual understanding of how both approaches coexist within managerial practices.

We do this through data analysis of managerial practices in six organizations, concentrating on the social negotiation of employment relations in areas such as recruitment and selection or payment. Figure 1 represents both our analytical approach and focus. As Misztal (2000, p. 4) argues, organization and management inevitably involves a combination of impersonal and procedural rules with more particularistic and local standards'. Drawing on the work of Elias (1978), Misztal conceptualizes informality and formality as a dualistic span, moving away from a dichotomous or contradictory understanding of organizing and managing, suggesting that both formalization and informalization can take place simultaneously. As Figure 1 suggests, the social negotiation of the synchronization process, in which owners, managers and employees seek to reach consensus through interaction, forms the analytical focus of this argument.

In particular, Misztal (2000) explores the potential that both formality and informality

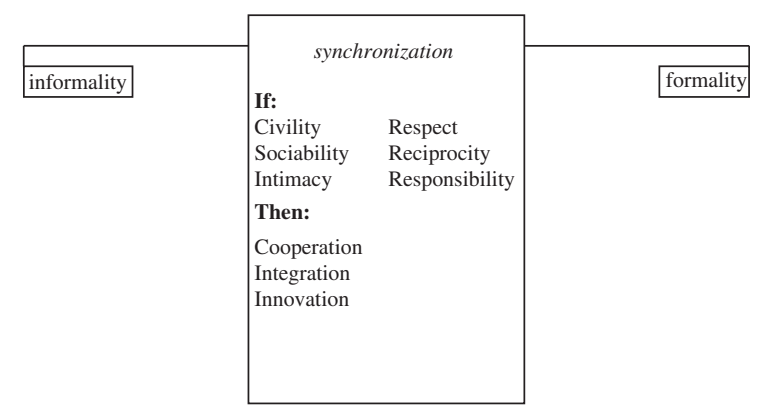

Figure 1. The informality-formality span and intermediate interactional practices (after Misztal, 2000) 
contain in some depth. She argues that we tend to identify formal practice with public, instrumental, macro and control, while we reserve informal practices for quite different functions - the affective, micro, private, social and integrative. If we start from the understanding that formality and informality are part of a single span, however, then they may be seen as resources to be mobilized, rather than predictable or fixed in their constitution and effects.

Accordingly, our analysis is intended to contribute to existing theory regarding the interface between and overlap of informal and formal managerial practices, with focus on employment relations in medium-sized firms. Smaller firms, as we noted at the outset, are a popular empirical site for researchers to explore formality and informality in managerial practice (see, for example, de Kok, Uhlaner and Thurik, 2006; Golhar and Deshpande, 1997; Kotey and Slade, 2005). However, perhaps as a legacy from the approach taken in the Aston studies of the late 1960s (see Pugh (1988) for a conceptual and methodological overview), conceptual focus rests on what is defined as a shift from informal to formal. It is this, above all, that we wish to challenge, in taking the interplay between informal and formal as our analytical centre. In addition, analysing the tensions and challenges of accommodating movements between informality and formality, and especially uneven and contested processes, will contribute to calls from Tansky, Heneman and Cohen (2003, p. 299), Harney and Dundon (2006, p. 156) and Phelps, Adams and Bessant (2007, p. 9) for more research which explores particularism in employment relations in small and medium-sized companies.

\section{Researching informality and formality}

The research on which our analysis is founded was designed to explore the process whereby growing firms adopt greater formality within the historical context of an informal employment relationship. We draw on the experiences and observations of employers, managers and employees. Formality and informality are, as we noted above, conceptually awkward to define and operationalize empirically. Formality, as a key component, has attracted more attention and is therefore more clearly defined (Misztal, 2000).
Informality tends to be conceptualized as residual, a nostalgic relic of pre-modernity. At best, informality is embedded in a commonsense way as practices that evade or challenge formality, face-to-face rather than procedural or bureaucratic. In most previous studies of employment relations in smaller organizations (Bacon and Hoque, 2004; Cully et al., 1999; Forth, Bewley and Bryson, 2006; Heneman, Tansky and Camp, 2000) the key indicator of formality is the number of identifiable employment policies and practices in place. This is problematic given the opportunities for the respondent (particularly if it is the firm owner) to over report the extent and complexity of policy. Such 'over claiming' has been exposed in work by Bacon et al. (1996) through the use of triangulation, and also in a qualitative study comparing employer and employee experiences of regulatory compliance by Marlow (2002). In this particular study, we explored the presence, recognition, and consistent and appropriate use of dedicated written policies and procedures within key areas of the employment relationship. This comprehensive remit underpinned the operationalization of the research question regarding changes within the formality-informality span as firms grow.

This enabled the avoidance of simplistic policy counting as an indication of embedded formality; instead we looked deeper into the presence of policies both in place and in practice. To ensure that this was possible, for all respondents our research schedule focused upon a discussion of the employment relationship from points of recruitment through to exit. As expected, there were subtle differences in the emphasis of the discussion. To take one example, recruitment and selection, owners and managers were asked to describe current practices, how these might have changed over time and any problems related to finding appropriate staff. Employees, however, were asked how they joined the organization and, dependent on length of service, were subsequently invited to comment upon how practices had changed. We also asked employees if they felt their experience was common to that of colleagues who had been with the organization for a shorter (or longer) period of time. This probing and discursive approach was adopted throughout. Accordingly, our data analysis is centred upon oscillations along the informality-formality span by examining the continuous negotiation 
and contestation of written policies and procedures as described by all three categories of respondent.

Clearly a qualitative approach to data collection was deemed essential to uncovering and exploring perceptions and experiences of employers, managers and employees. We began from the base that all involved in the employment relationship actively construct and reconstruct the employment relationship formally and informally. In this we respond to frequent calls for more such research in the field of employment relations, to investigate the actual as opposed to the espoused, capturing the reality of workplace practice for example, on the presence or absence of a formal procedure' (Dickens and Hall, 2005, p. 34). This approach facilitates a contextual exploration of the shifting employment relationship in growing firms; as Harris and Ogbonna (2007, p. 10) note, this approach is vital to achieving 'a deeper understanding, full contextual sense of studied phenomena and an appropriate foundation for innovative theory development'. This complements the argument made by Ram et al. (2001, p. 849) regarding the contribution of case study work to conceptual argument: 'we are not seeking to generalise to a population but to examine "soft" processes and dynamics ... we generalise to the level of theory rather than any notion of representativeness'. The narratives collected are thus seen as providing an 'empirical coat-hanger' (Ditton, 1977, p. 9) upon which to rest theoretical analysis.

The specific difficulties of gaining research access to smaller organizations are well recognized (Curran and Blackburn, 2001). Given the academic and popular representation of smaller firms as deficient in the adoption of best practice policy, particularly regarding labour management, getting into firms can be difficult (Ram, 1994). This challenge was mitigated through working with a professional accountancy firm that assisted in identifying organizations and effecting introductions. Accountants retain a high degree of trust both in their professional capacity and as business advisors for smaller organizations; they have been described as a legitimate business 'friend' (Mole, 2002). In circumstances where firm owners and managers are asked to reveal informal or idiosyncratic practice to external scrutiny, reticence can be expected. Consequently, having an 'introduction' was invaluable. The six firms which formed the basis of the study reflect a mixed case approach (Dyer and Wilkins, 1991; Eisenhardt, 1989, 1991), but had all grown from small (fewer than 49 employees) to medium-sized (50-249 employees) firms in the last two years. Eisenhardt proposed the strengths of the multiple case study approach as providing 'novelty, testability and empirical validity' (p. 548), enabling the emergence of clearer constructs and 'better' stories. For our purposes, a mixed case approach facilitates the exploration of differentiated progression within the informality-formality span. The case studies were constructed from repeated interviews lasting between one and three hours with employers, employees and managers. Only one organization (ChefCo) had a full time, Chartered Institute of Personnel and Development (CIPD) qualified HR manager in post. Other firm characteristics are described in Table 1.

All six firms had experienced employee-related growth in the two years preceding data collection, making the transition from 'small' to 'medium' sized according to respondents. The dynamics

Table 1. Case study organization characteristics

\begin{tabular}{|c|c|c|c|c|c|c|c|c|}
\hline \multirow[t]{3}{*}{ Firm } & \multicolumn{4}{|c|}{ Size } & \multirow[t]{3}{*}{ Sector } & \multicolumn{2}{|c|}{ Turnover (millions) } & \multirow[t]{3}{*}{ Age (years) } \\
\hline & \multicolumn{2}{|c|}{2004} & \multicolumn{2}{|c|}{2006} & & \multirow[t]{2}{*}{2004} & \multirow[t]{2}{*}{2006} & \\
\hline & \multicolumn{2}{|c|}{ Full-time Part-time } & \multicolumn{2}{|c|}{ Full-time Part-time } & & & & \\
\hline BoxCo & 38 & 3 & 72 & 6 & \multicolumn{2}{|c|}{ Manufacturing 4.1} & $5+*$ & 12 \\
\hline HaulCo & 45 & 4 & 85 & 4 & Haulage & 3.8 & $5+*$ & 13 \\
\hline IntelCo & 48 & 12 & 68 & 10 & Training & 3.1 & $5+*$ & 9 \\
\hline WomCo & 36 & 10 & 58 & 25 & Services & 2.7 & 3.3 & 9 \\
\hline PropCo & 40 & 6 & 84 & 8 & Developer & 11 & 18 & 16 \\
\hline ChefCo & 47 & 5 & 64 & 4 & Manufacturing & $5+*$ & $5+$ & 12 \\
\hline
\end{tabular}

*Turnover not specified but given as more than 5 million pounds. 
and challenges associated with this shift were discussed readily by all respondents. We probed extensively around the application of current policies and differences in perception between the owners, managers and employees. Reflecting recent work by Harney and Dundon (2006), this more 'holistic' approach results in the exploration of the entire domain of labour management rather than isolating individual practices. Finally, we asked respondents to describe critical incidents associated with managing the employment relationship and to identify the impact of any such events.

In data analysis we followed the precepts of 'ethnographic content analysis' (Altheide, 1996). All interview transcripts were read in their entirety by each author to construct an initial set of coding categories. These themes and issues were refined through testing intercoder reliability and reflexive, recursive readings through the lens of our conceptual framework. We were then able to further develop our initial thematic analysis conceptually and to orient our data analysis to the informalityformality span.

\section{The span of formality and informality}

\section{Formal introductions}

We found respondents in all six firms identifying a shift towards formality through key events in managing the employment relationship. This was especially evident in accounts of recruitment and selection, appraisal, and grievance and discipline. In the one organization which employed a professional HR manager, ChefCo, increasing formality in employment relations was linked to improvements in individual performance, managerial procedures and customer relations:

People are much more efficient, they feel more secure, we have better communications, training and systems, so we present a better image to customers. (HR manager, ChefCo)

However, ChefCo's owner associated this formality with an associated change in the social relations of production:

It has become much more difficult to treat people as individuals; they are much more legal entities. I do think that you have to create a formal structure but it has dehumanized a lot of work relationships, which is a shame.

This sentiment was common to all owners and managers, lamenting the intrusion of formality into what they presented as previously amiable social relations.

At one time, I knew all of my staff members personally; now I couldn't tell you $50 \%$ of their names on sight. It means I have to delegate control and you lose the personal touch, it does upset me.

(Owner, PropCo)

The owners and managerial respondents all agreed that a more formal approach to labour management had been adopted as a response to growth in employee numbers. Whilst many identified one critical event, there were also many general references to difficulties in sustaining informality as social ties became stretched and the need to present a more 'professional image' arose. At ChefCo, the HR manager felt that

Our reputation was suffering, customers were not getting the right deal; we had to sharpen up.

At PropCo, however, formalization was presented as a result of internal organizational complexity:

There comes a point when you just can't do the whole job on a nod. I tried to relate to people like it was still a family but some just took advantage so I realized, these are not friends who happen to work for me but people who just work for me - it was tough.

When employees reflected on changes in the organizations, many expressed sentiments similar to a long-standing employee at PropCo:

Well, I think they have carried on trying to do things the same way but just making adjustments here and there to try and make it carry on working - but it does fall apart.

At HaulCo, the employer described the use of various HR policies and practices in some detail; however, employees presented labour management practices as 'chaotic'. One summarized this situation:

They are trying to get things better but it's never changed much really. They say different things now but we just do the same; I really hope it gets better.

These comments reveal both the contested nature of change and the potential for employee 
commitment to formalization in growing organizations. This casts doubt on the accounts of owners and managers lamenting the displacement of social proximity. Employees in all organizations perceived a more negotiated and fluid environment where informality and formality overlapped, with leakage through the boundaries.

Initially, therefore, we find that formalization is presented as inevitable, driven by internal organizational dynamics and customer demands, to maintain the organization of employment relations in a semblance of order. Employers expressed most regret for the loss of 'family' or 'friendly' social relations, yet employee experience suggested that formality and informality existed alongside each other, negotiated and contested.

\section{Policy and practice}

To explore this dynamic in more detail, we sought specific examples of formality and informality within the employment relationship. It is notable that at the single organization that employed an HR manager, ChefCo, we found a broad range of policies in place and used as norms. The firm owner and employees all demonstrated familiarity with established formal processes. The employment relationship had been reordered to reflect a higher degree of formality, and all agreed that the HR manager had authoritatively taken 'ownership' of the people management function in a respectful and responsible way. However, such embedded formality was absent in the other five firms. In all of them, the owner or chief executive and a 'manager' (in most cases the owner's personal assistant) took joint responsibility for managing the employment relationship. The information they drew on to construct policy and guide practice was drawn from a range of sources, including ACAS, consultants, business advisors, accountants, seminar attendance and the internet. When prompted to describe the current employment relationship, all respondents spoke of how attempts had been made to formalize, but responses also consistently indicated a fluid notion of formality in implementation.

This is particularly clear in recruitment and selection. Managers in all six firms used formal recruitment methods such as advertising, job centres or employment agency referrals; none would admit to systematic use of 'grape vines' or kin relations to find staff. However, at HaulCo a driver supervisor explained:

Look around here, they're all related to [the owner], they have to work here, they couldn't get a job anywhere else!

In practice then preferred applicants were 'encouraged' to apply for formally advertised posts and given priority in the selection process. Selection interviews also lacked the features of good practice guidelines in the area, perhaps reflecting an absence of expertise. At WomCo formal advertising was used as the norm, yet respondents all noted that no-one had been trained in interviewing techniques or protocols. At the time of data collection the selection process was in fact dependent on an agency employee, employed as a book keeper, who was willing to lead in interviews for permanent members of staff. She commented:

Well, they are all a bit hopeless - it's not rocket science, ask appropriate questions, assess if they can do the job and if they are not obviously bonkers they will probably be alright.

At IntelCo the managing director, who had bought into the firm during its growth period, had previously been employed as an HR director in a larger organization. When he arrived he understood that recruitment and selection were managed through formal processes; however, it rapidly became evident that this was not quite the case in practice:

... the manager responsible placed proper adverts ... but it was amazing what people ended up here. He words it [the advert] in such a way to suit the people he wants to apply and strangely, they get the job.

Thus, we find that there was collusion between owners, managers and employees to attract and favour certain new recruits through family links, patronage and pragmatism. The boundary between formality and informality was easily broached.

We found a somewhat bizarre illustration of this at HaulCo; an employee recounted the process of appointing a new receptionist through a formal recruitment and selection process. However, the finance director's daughter, who worked part-time at the firm to supplement her income as a spiritual medium, decided that the new receptionist was a 
'white witch' and encouraged managers to lobby for her dismissal. The new receptionist was indeed asked to leave during her probation period, and the finance director's daughter insisted the firm spend a considerable sum of money having all traces expunged from the building by a feng shui practitioner. Numerous other employees confirmed this tale, and indeed presented it as an illustration of the ongoing struggle between the owner's PA, who had been given the task of formalizing employment relations, and the 'old guard' management who saw the firm as their private empire. One commented:

I feel sorry for [the PA] - it doesn't matter how hard she tries and gives out all this 'we do things properly here' guff, they [the owner and managers] just do what they feel; [it] makes us laugh.

Appraisal is the second pivotal area in which formality and informality are contested. Four firms either had implemented formal appraisal systems or were in the process of doing so; HaulCo and BoxCo had no formal structures in place. Most owners gave an impression of considerable formality; PropCo for example had achieved Investors in People (IiP) status which, among other things, requires the introduction of formal appraisals. PropCo's owner insisted appraisals were

conducted more as an open discussion to ascertain training requirements, strengths and weaknesses. It is not about hauling people over the coals; we also have a competency register that everyone agrees to; it sends a positive message; we are planning properly for the future now.

When employees were asked about their experiences of the appraisal system, however, one claimed that

People were unhappy about it as the bosses blurted out who had filled in the 360 degree form.

Another noted:

This year instead of filling in the forms yourself the appraiser just asked you verbally and wrote down what you said, but as the same people always appraise the same people, if you didn't like that person, you could just give them bad feedback every year. They got IiP last year but we were all told to lie.

The coexistence of formality and informality is clear, as is the lack of respect and reciprocity in the process, leaving employees and managers with a lack of understanding of why the process is taking place. Whilst we found that appraisal frameworks had been professionally established, by mutual consent managers and employees were able to shape the system to achieve desired results, often with the knowledge of the owner. In addition, it appears that IiP status was being used as a benchmark of credibility to signal formality to customers and potential recruits, but that in practice there was a considerable degree of mock compliance.

We found a similar pattern with grievance and discipline procedures; all organizations had formal written policies but managers and employees implemented them in radically different ways. In keeping with her overall approach, the HR manager at ChefCo encouraged line managers to bring all issues, however minor, to her attention; managers and employees agreed that this happened in practice. This is again contrasted with the situation at WomCo where polices were in place but, as one employee remarked,

They are not really used - people generally sort it out there and then between themselves.

This was identical to accounts given at PropCo and HaulCo. At BoxCo one incident stimulated more implementation of procedure, as the owner told us:

One day I came across a section manager having a row with one of the blokes - he can be a bit bolshie, and the manager was on for it. I had to calm it right down. In the past a bit of banter and shouting might sort it out but not now, we're too big and it's too risky.

This oscillation between formal and informal was confirmed by BoxCo employees; they felt there was little point in raising grievances formally as little would be done and that established social networks persisted if they wanted to circumvent formal systems. However, one did comment:

If someone was really in trouble we used to see it, but now this doesn't happen as much - it usually gets taken upstairs and sorted, we don't get to see it quite as much anymore, but not much comes to that.

In terms of compliance with employment regulation we found limited concern or acknowl- 
edgement. This stance is effectively summarized by the owner of BoxCo:

We pay above minimum wage, I am sure we are not affected by the [Working] Time Directive, if people want time off they ask, so even though we were flooded by material and dire warnings in the post about what could happen, everything just rolls on.

All respondents were asked if, or how, any of the many recent British employment regulations affected operations. Very little dialogue ensued; the impact appeared minimal and there was low awareness even of the existence of some regulatory frameworks. This echoes Ditton's (1977) experience when researching pilfering in organizations, in that there were many painful, embarrassed, stilted interactions about this theme. What emerges is a picture of growing frameworks for the formal ordering of employment alongside continued adherence to informality which draws upon patronage, ignorance and prerogative. It is a truism that employees and managers in larger organizations also depend upon informal relationships to ease the labour management process; however, the difference we found in these six medium-sized companies is the inability of either managers or employees to mobilize formal policy or procedure to shape the interaction of formality and informality.

\section{Change and consistency}

This dynamic is clear when we examine the critical incidents respondents gave when asked to identify a moment that exemplified the interplay of formality and informality in employment relations. At ChefCo, owners decided to pursue formalization when a consultancy report identified links between falling performance levels, informal managerial practices and inefficient labour management. The owner's PA was (informally) 'promoted' into the newly created post of HR manager; she grasped the opportunity to study for a professional qualification and gradually introduced formal practices. Respondents suggested that creating the role of HR manager had the effect of diluting and deflecting the idiosyncratic and autocratic influence of the owner and management team, allowing a more professionalized approach to emerge. The HR manager recognized that initially her appointment caused problems as some senior managers were reluctant to 'let go' of day-to-day employee management, but that now

I've done this for a few years now and I had to fight for it; it is very formal now. The Chief Exec [owner] and managers were quite bullying and we had tribunal cases we were lucky to win. Now though, it's different, the Chief Exec backs me up and we are doing well.

The analytical interest in this case lies in the determination of the HR manager to embed formality, to provide her and her role with value and credibility. Her familiarity with the firm, particularly established micropolitical networks, and influence with the owner were central to her taking control of the employment relationship:

It was a nightmare at first - I had to make sure I really knew my stuff and keep the CE [owner] with me otherwise the others would have simply got me out; I know that for a fact.

This combination of professionalism and patronage enabled her both to construct her own managerial role and achieve authority. Informality and formality thus come together in the management of the structural conditions of the employment relationship and the redefinition of the relationship between formality and informality in the organization.

At IntelCo, attempts to introduce a higher degree of formality prompted the critical incident recounted by a number of respondents. Moves towards formality created resentment against the owner from his own management team, who objected in particular to 'interference' and a change in his 'manner', complaining persistently to him regarding his conduct. The owner wryly described this chapter in the organization's history as 'character forming', and reflected:

I had to break down barriers, take the staff with me. We went through two years to sort it out but unless you put it in [formality] and bed it down and enforce it, it slips back to the old ways. I know it still happens, I know there is a still a sense of 'not what but who you know' here. It will take time for this to go.

The owner made use of an HR consultant who visited the firm regularly to update and advise on policy and practice. In this case, the contestation of increased formality from managers reveals the complex process of renegotiating the employment relationship, and the fragility of relationships in 
small and medium-sized organizations. The introduction of greater formality challenged existing authority and networks which formed a web to hold the informal employment relationship together. The process of disassembling such links and re-forging them with differing boundaries created considerable disruption and resentment at IntelCo.

Two firms, WomCo and PropCo, had been threatened with employment tribunal applications from disgruntled employees. When asked about this, the chief executive of WomCo described how a director had persistently bullied office staff. No one really knew how to deal with the situation, in part as no formal policies were in place and it was unclear who had the authority to challenge the director. Eventually, there was a public argument and a collective complaint was articulated by office staff; the director resigned, but then threatened to go to tribunal to challenge the accusation, with the result that she was paid compensation for the loss of her position. At the time of the research, senior managers were planning to appoint an HR manager to 'turn it all around, to make sure this never happens again, we have all talked about the necessity of changing things but it is just finding the time'.

At PropCo, the owner had been accused of sexual harassment and threatened with a tribunal application:

I suppose this made us realize we needed proper procedures to deal with these events when we can't settle informally. Until then I really would have said it was like a family here, I thought everyone got on. This hit like a bolt from the blue; it was resolved with apologies and the person left with a deal, but to be honest, I was very upset - it made me realize that you can't have a bit of fun, we went for IiP to tighten up our procedures. I'd like to think that wouldn't happen again.

This owner frequently referred to IiP accreditation as evidence of formality in employment relations, but when employees were asked to comment a different picture emerged. A number claimed that bullying was a feature of the organization, and cited a recent incident in which the owner's personal assistant had encouraged adherence to formal policy and practice and caused friction with a long-standing director. The story continued:

\begin{abstract}
She went away on holiday and when she came back they told her she had to leave. We know that [the director] had gone to [the owner] and just complained all the time. She [the personal assistant] was told to tell us she was being made redundant but that's a lie, she was really upset and I know they have had to pay her off because I've seen her since.
\end{abstract}

Here an attempt to introduce more formality that required redistribution of power away from informal networks and influence was met with overt resistance.

HaulCo and BoxCo shared a similar event that encouraged formalization, the loss of a major customer prior to their recent period of growth. Managers at BoxCo decided to make redundancies to reconfigure the workforce and make space for new skills, but were unsure of how to approach the process. ACAS were consulted and a redundancy process was initiated but managers recognized that a weakness had been exposed. The process had left scars, as the owner remarked:

We had to get rid of some of the 'old guard'. I needed new people with different skills to capture better orders. I just didn't know how to do it and it become very personal. Still makes me wince to think of it.

At HaulCo, given the level of labour turnover (around $50 \%$ per annum), it was easy to 'let people go', helped by the fact that few of the drivers had a formal contract of employment. During a recent period of expansion, attention had been given to labour management and associated costs. The PA responsible for this area presented the persistence of informality as problematic, candidly stating that the biggest problem was the owner, especially

stopping [him] from still doing everything and undermining my authority - it's difficult as he owns the place! Also, we need to get a professional tier of managers in, which we have started to do, and get rid of the family - we need the right people in the right jobs.

The firm had taken on two new managers at considerably higher salaries than existing staff with the express aim of professionalizing and formalizing the organization to facilitate growth. The payroll clerk was not quite so positive about the extent of change: 
Everyone here is on weekly pay because they [the owners] can't afford a monthly pay roll; the new managers earn loads more than the others, there will be hell to pay if they find out. I feel sorry for [the PA], she is really trying but the old guard here, they don't like it - they make her job so hard.

This employee perspective again exposes the problems associated with trying to formalize the employment relationship, indicating again that it is a far more complex process than simply identifying formal policy and writing procedures.

The examples explored here expose the contested, complex nature of the employment relationship. Differential perceptions of events and managing confidentiality are all part of daily life within organizations. Yet, during periods of flux and change when power relations are shifting, when new employees are penetrating established teams, when old networks and loyalties are being stretched and reconstructed, the problems of a changing informality-formality span become far more transparent. The challenge in embedding formality within informality is gaining managerial and employee consent to do so when personal influence and power becomes forfeit to normative policy. The problematic nature of attempting this process for all concerned in the employment relationship is the subject of our final section.

\section{Conclusion: synchronizing the formality-informality span}

Lest this analysis be misinterpreted, it is worth emphasizing that we are not attempting to challenge the established wisdom that increasing size and complexity fosters greater formality; indeed in our data this dynamic is clearly signalled by the adoption of a range of HR policies and some professionalization of the HR function. However, alongside this it is equally clear that, during the introduction and implementation of such changes, owners and managers in particular expressed a sense of regret and nostalgia for the loss of what they presented as benign fraternalism or 'friendly' social relations of production. Employees were, on the whole, less convinced this had disappeared. There was recognition of, and some adherence to, formality but the desire in both managers and owners to retain informal control over the employment relationship ensured that embedding formality as unquestioned normative policy was an uneven process.

ChefCo was the most formal organization; we would suggest this was largely due to the presence of a professionally qualified HR manager who had achieved legitimacy in the eyes of colleagues and managed to introduce and embed formal policy and practice. In other cases, the task of formalizing labour management was more contested, with owners, managers and employees recounting different perceptions and experiences of formality. External frameworks and actors, such as IiP and consultants, were both present in case study organizations but were perceived as largely ineffective by employees. While there is a consistent assumption of the need for greater formality as firms grow, it appears that making this transition is challenging for all concerned. The complex web of power and influence which shapes the employment relationship becomes transparent in growth firms. Unlike studies of informality in small and micro firms (those employing fewer than 49 people) which describe the process of negotiation between employees and employers, these larger, growing firms reveal the interactional dynamics of negotiation between multiple groups. The points of tension arise from decisions to introduce formalization which requires established networks of influence to be renegotiated. Of considerable interest here is the degree of overt and covert managerial resistance to change, even though all managerial respondents recognized this as an impediment to growth and sustainability. The reconfiguration of managerial authority, we would suggest, is a key challenge for such organizations. Appropriate and effective managerial responses to the problems which arose during the process of reordering the employment relationship were patchy and uncertain, and employees were affected by changes to lines of communication and influence. The organizations, however, were small enough and managerial hierarchies sufficiently transparent for established networks and affiliations to retain influence. Moreover, employees often maintained links with owners and preferred managers, rather than working with the designed individual responsible for the employment relationship which in effect further undermined the formality agenda.

In sum, then, we are suggesting that negotiating growth is not simply about recognizing the 
need for and introducing policies to formalize employment relations. It also requires employees, owners and managers to acknowledge and accept the redistribution of authority that the process demands, interactionally as well as procedurally. Our analysis here supports the arguments made by Phelps, Adams and Bessant (2007) that the growth process is uneven and unpredictable, involving periods of progression and regression in a context of contested authority. It is axiomatic that, as organizational growth occurs, greater formalization becomes necessary to effectively and efficiently manage labour but we have argued that little is known regarding this process (Forth, Bewley and Bryson, 2006; NichollsNixon, 2005). This is despite recent theoretical development, particularly the work of Misztal (2000), which might inform analyses of the dynamics of formality and informality. As such the spaces that formal and informal employment relations occupy, when reordered, have the potential to both draw on and contribute to this area. All organizations operate through a nexus of formality and informality. This nexus, or span, exists within uncertain boundaries which change over time, are contested and are based upon structured antagonism (Edwards, 2003) such that even within bureaucratic and complex organizations degrees of informality are essential for the labour process to operate effectively. This paper has explored the process of reconfiguring the employment relationship during the uncertain process of embedding formality as normative practice.

The existing evidence regarding the dynamic manner in which informality and formality occupy spaces in the employment relationship in small, medium and large organizations has become increasingly sophisticated. However, research now needs to explore the process whereby formal policy comes to be perceived and understood as the legitimate response to managing the employment relationship as organizations become more complex. Whilst accepting the underlying logic of structured antagonism, the manner in which this is renegotiated in a context of firm growth requires further scrutiny. In the light of this discussion and especially through our analysis drawing on Misztal's (2000) work in this context, we suggest that particular attention should be given to the role of managers in defending their authority during the dilution of power through greater delegation. Such analyses could also shed light upon the place of informality in formal employment relationships. In particular, we would suggest that the use of the informality-formality span to negotiate the rigidities of normative approaches to facilitate differing degrees of human autonomy, whilst guiding effort towards organizational objectives, provides a potentially rich area of continuing inquiry.

\section{References}

Altheide, D. (1996). Qualitative Media Analysis. Thousand Oaks, CA: Sage.

Bacon, N. and K. Hoque (2004). 'HRM in the SME sector: valuable employees and coercive networks', International Journal of Human Resource Management, 16, pp. 1976-1999.

Bacon, N., P. Ackers, J. Storey and D. Coates (1996). 'It's a small world, managing human resources in small businesses', International Journal of Human Resource Management, 7, pp. 82-100.

Barrett, P. and M. Sexton (2006). 'Innovation in small, projectbased construction firms', British Journal of Management, 17, pp. 331-346.

Brown, W. (1973). Piecework Bargaining. London: Heinemann.

Burawoy, R. (1979). Manufacturing Consent: Changes in the Labour Process under Monopoly Capitalism. Chicago, IL: University of Chicago Press.

Cully, M., A. O'Reilly, N. Millward, J. Forth, S. Woodland, G. Dix and A. Bryson (1999). The 1998 Workplace Employee Relations Survey. London: Routledge.

Curran, J. and R. Blackburn (2001). Researching the Small Enterprise. London: Sage.

De Kok, J., L. Uhlaner and A. Thurik (2006). 'Professional HRM practice in family owned-managed enterprises', Journal of Small Business Management, 44, pp. 441-460.

Dickens, L. and M. Hall (2005). 'The impact of employment legislation: reviewing the research'. DTI Employment Relations Research Series 45.

Ditton, J. (1977). Part-time Crime: An Ethnography of Fiddling and Pilferage. London: Macmillan.

Dyer, W. G. and A. L. Wilkins (1991). 'Better stories, not better constructs to generate a better theory: a rejoinder to Eisenhardt', Academy of Management Review, 16, pp. 613619.

Edwards, P. (1986). Conflict at Work. Oxford: Blackwell.

Edwards, P. (ed.) (2003). Industrial Relations. Oxford: Blackwell.

Edwards, P. and M. Ram (2006). 'Surviving on the margins of the economy: working relations in small low wage firms', Journal of Management Studies, 43, pp. 895-916.

Eisenhardt, K. M. (1989). 'Building theories from case study research', Academy of Management Review, 14, pp. 737-770.

Eisenhardt, K. M. (1991). 'Better stories and better constructs: the case for rigor and comparative logic', Academy of Management Review, 16, pp. 620-628.

Elias, N. (1978). The Civilizing Process. Oxford: Blackwell. 
Forth, J., H. Bewley and A. Bryson (2006). Small and Medium Sized Enterprises: Findings from the 2004 Workplace Employment Relations Survey. London: DTI.

Freidman, A. (1977). Industry and Labour. London: Macmillan. Gillman, M., P. Edwards, M. Ram and J. Arrowsmith (2002). 'Pay determination in small firms, the response to the National Minimum Wage', Industrial Relations Journal, 33, pp. 52-68.

Golhar, D. and S. Deshpande (1997). 'HRM practices of large and small Canadian manufacturing firms', Journal of Small Business Management, 35, pp. 30-38.

Harney, B. and T. Dundon (2006). 'An emergent theory of HRM: a theoretical and empirical exploration of determinants of HRM among Irish SMEs', Advances in Industrial and Labor Relations, 15, pp. 109-159.

Harris, L. and E. Ogbonna (2007). 'Ownership and control in closely held family firms', British Journal of Management, 18, pp. 5-26.

Heneman, R., J. Tansky and M. Camp (2000). 'HRM practices in SMEs', Entrepreneurship, Theory and Practice, 25, pp. 1126.

Kotey, B. and P. Slade (2005). 'Formal human resource practices in small growing firms', Journal of Small Business Management, 43, pp. 16-40.

Marchington, M., M. Carrol and P. Boxall (2003). 'Labour scarcity and the survival of small firms', Human Resource Management Journal, 13, pp. 5-22.

Marlow, S. (2002). 'Regulating labour management in small firms', Human Resource Management Journal, 12, pp. 5-25.

Marlow, S., Patton, D. and Ram, M. (eds) (2005). Managing Labour in Small Firms. London: Routledge.

Mazzarol, T. (2003). 'A model of small business HR growth management', International Journal of Entrepreneurial Behaviour and Research, 9, pp. 27-49.
Misztal, B. (2000). Informality: Social Theory and Contemporary Practice. London: Routledge.

Mole, K. (2002). 'Business advisers' impact on SMEs', International Small Business Journal, 20, pp. 139-162.

Moule, M. (1998). 'Regulation of work in small firms: a view from the inside', Work, Employment and Society, 12, pp. 635653.

Nicholls-Nixon, C. (2005). 'Rapid growth and high performance: the entrepreneurs impossible dream?', Academy of Management Executive, 19, pp. 77-89.

Phelps, R., R. Adams and J. Bessant (2007). 'Life cycles of growing organizations', International Journal of Management Reviews, 9, pp. 1-30.

Pugh, D. (1988). 'The Aston research programme'. In A. Bryman (ed.), Doing Research in Organizations. London: Routledge.

Rainnie, A. (1989). Industrial Relations in Small Firms. London: Routledge.

Ram, M. (1994). Managing to Survive. London: Routledge.

Ram, M. and P. Edwards (2003). 'Praising Caesar not burying him: what we know about employment relations in small firms', Work, Employment and Society, 17, pp. 719-730.

Ram, M., P. Edwards, M. Gilman and J. Arrowsmith (2001). 'The dynamics of informality, employment regulations in small firms and the effects of regulatory change', Work, Employment and Society, 15, pp. 845-861.

Roethlisberger, F. and W. Dickson (1939). Management and the Worker. Cambridge, MA: Harvard University Press.

Tansky, J., R. Heneman and D. Cohen (2003). 'Managing people in entrepreneurial firms'. Paper presented to the 23rd Babson Kauffman Entrepreneurship Research Conference, Wellesley, MA, June.

Wilkinson, A. (1999). 'Employment relations in SMEs', Employee Relations, 21, pp. 206-217.

Susan Marlow is Professor of Entrepreneurship and Small Business at De Montfort University. She has researched and published extensively in the areas of gender and entrepreneurship and labour management in small firms. Susan has been to the USA as visiting professor on a number of occasions and has worked with the European Union on entrepreneurship issues. She is consulting editor to the International Small Business Journal and a board member of the Institute of Small Business and Entrepreneurship.

Scott Taylor is Senior Lecturer in Leadership Studies in the Centre for Leadership Studies at the University of Exeter. His research focuses on the employment relationship in smaller organizations, and religion/spirituality in organizations. He has published work in the British Journal of Industrial Relations, Human Resource Management Review and Journal of Management Education analysing the establishment of management legitimacy in small firms, Investors in People, and the dynamics of recruitment and selection.

Amanda Thompson is Principal Lecturer in Human Resource Management at De Montfort University. Amanda is a fellow of the Chartered Institute of Personnel and Development and has extensive experience of the tensions surrounding the establishment and embedding of the HR function in organizations. 


\section{Author Query Form}

\begin{tabular}{ll}
\hline Journal & BJOM \\
Article & 635 \\
\hline
\end{tabular}

Dear Author,

During the copy-editing of your paper, the following queries arose. Please respond to these by marking up your proofs with the necessary changes/additions. Please write your answers clearly on the query sheet if there is insufficient space on the page proofs. If returning the proof by fax do not write too close to the paper's edge. Please remember that illegible mark-ups may delay publication.

\begin{tabular}{|c|c|c|}
\hline Query No. & Description & Author Response \\
\hline Q1 & AQ: Gilman et al 2002 is written as Gillman et al 2002 in the references. Which is correct please? & \\
\hline Q2 & AQ: Should Marlow 2005 be Marlow, Patton and Ram 2005 as in the references? If not please give details. & \\
\hline Q3 & AQ: Gilman et al 2003 isn't in the reference list. Please give details. & \\
\hline Q4 & AQ: Sen-Gupta 2007 isn't in the references. Please give details. & \\
\hline Q5 & AQ: Please give publication details & \\
\hline Q6 & AQ: Marlow 2002 doesn't have a page 4. Please check. & \\
\hline Q7 & AQ: Friedman is spelt Freidman in the references. Which is correct please? & \\
\hline Q8 & AQ: de Kok is written De Kok in the references. Which is correct please? & \\
\hline Q9 & AQ: Please identify where this page number is from - it's not from either of the Eisenhardt references. & \\
\hline & & \\
\hline & & \\
\hline & & \\
\hline & & \\
\hline
\end{tabular}

